\title{
EMPRÉSTIMOS LITERÁRIOS EM UMA BIBLIOTECA: INDÍCIOS DAS LEITURAS DE ESTUDANTES
}

\author{
LITERARY LOANS IN A LIBRARY: \\ STUDENT READING INDICATORS
}

\author{
Rosana Carvalho Dias Valtão*
}

\begin{abstract}
Resumo: Este trabalho interessa-se por conhecer as obras literárias lidas por estudantes do ensino médio de uma instituição pública de ensino técnico, a partir da biblioteca escolar. No contexto desta pesquisa, propõe-se uma investigação das práticas de leitura literária a partir das obras retiradas pelos alunos do IFES/Campus de Alegre do acervo da biblioteca escolar no contexto contemporâneo de novos suportes, de diversidade de produção e da indústria cultural. Para isso, este estudo dialogará com os conceitos de leitura literária, produção de sentido, comunidade de leitores e mediação nas perspectivas da História Cultural e nas contribuições de Roger Chartier para o estudo do livro e da leitura.
\end{abstract}

Palavras-chave: Leitura Literária. Comunidade de leitores. Biblioteca Escolar. Ensino Médio.

Abstract: This work is interested in knowing the literary books read by high school students of a public technical education institution, from the school library. In the context of this research, we propose an investigation of literary reading practices, from the books taken by the students of IFES / Alegre, considering the school library collection in the contemporary context of new media, diversity of production and cultural industry. Therefore, this study will dialogue with the concepts of literary reading, production of meaning, community of readers and mediation, taking the perspectives of cultural history and the contributions of Roger Chartier to the study of books and reading.

Keywords: Literary Reading. Community of readers. School library. Secondary school.

\section{Considerações iniciais}

São frequentes, nos debates cotidianos, inquietações frente às práticas de leitura, no século XXI, de uma geração da qual se diz que seja imediatista, impaciente, consumista e inserida em uma era caracterizada por grandes avanços tecnológicos, em que várias ações são feitas, registradas, compartilhadas, vistas e comentadas em um curto espaço de tempo - o que, a princípio, no senso comum, seria um entrave à realização das leituras literárias que, tradicionalmente, gozam de maior prestígio social. É comum supor que, nesse cenário, as práticas de leitura sejam fragmentadas, superficiais e que os sujeitos nelas engajados estejam em busca de leituras mais simples e objetivas, com parágrafos curtos e linguagem direta, que não demandem grandes investimentos por parte dos sujeitos para a produção de sentidos.

No entanto, a despeito disso, nota-se que muitos dos frequentadores de livrarias são jovens; muitos dos resenhistas em sites, blogs e redes sociais constituídos em torno da leitura (como, por exemplo, o Skoob) são jovens; os youtubers que mais fazem sucesso comentando obras literárias na Internet são jovens. Assim, configura-se imprudente supor que as gerações mais jovens não leiam ou leiam pouco - mesmo quando restringimos o recorte a textos ficcionais. Desse modo, afigura-nos necessário indagar sobre as práticas de leitura literária desses sujeitos; um bom modo de fazê-lo, nos parece ser começar por tentar descobrir o que efetivamente leem.

\footnotetext{
* Professora do Instituto Federal do Espírito Santo. Mestre pela Universidade Federal do Espírito Santo. rosanad@ifes.edu.br
} 
Com o objetivo de conhecer especificamente o que leem os jovens alunos do Instituto Federal do Espírito Santo, no campus de Alegre, este trabalho debruça-se sobre os empréstimos de obras literárias realizados pelos estudantes da instituição no ano de 2013. Perguntamos: Quais são as obras que os estudantes da instituição em foco mais tomam emprestadas do acervo da biblioteca escolar? Que indícios sobre as práticas de leitura esses dados quantitativos nos fornecem?

As discussões em torno dos temas eleitos para essa investigação foram norteadas pelos princípios da História Cultural, especialmente pelas contribuições do historiador francês Roger Chartier no que se refere ao estudo do livro e da leitura. Os dados para a pesquisa foram produzidos levando em conta as lições chartierianas, a partir de distintas fontes: questionários com questões abertas aplicados aos responsáveis pela biblioteca escolar da instituição em estudo; tabulamento de dados objetivos sobre os empréstimos de obras literárias realizados por alunos da instituição e sobre as obras mais emprestadas aos alunos que mais retiraram obras do acervo em questão; e informações oficiais fornecidas pelo site institucional.

\section{A leitura literária em busca de sentidos}

A leitura neste trabalho é entendida como uma atividade de produção de sentidos, como prática enunciativa complexa mediada pelo texto, visando à interlocução por meio da palavra escrita. Jean Marie Goulemot reforça essa dimensão enunciativa, pois entende que a produção de sentidos por meio da leitura de um texto escrito se dá com base em leituras anteriores, ou seja, a biblioteca interior ou particular do sujeito leitor coopera na apropriação e objetivação do que é lido: "o sentido nasce, grande parte, tanto desse exterior cultural quanto do próprio texto e é bastante certo que seja de sentido já adquiridos que nasça o sentido a ser adquirido" (in CHARTIER, 2011, p. 114).

Marlène Lebrun (in REZENDE, 2013, p. 139), por sua vez, afirma que o leitor precisa se apropriar do texto para compreendê-lo: é nesse jogo que acontece o confronto entre mundo do leitor, sua história, suas outras leituras e o texto a ser lido ou em processo de leitura. É nessa relação que o indivíduo se forma, constitui-se como sujeito social e constrói suas relações culturais. Sem isso, a atividade fica restrita à mera decodificação de símbolos sem nenhum sentido.

Nessa perspectiva, a leitura não é vista apenas como operação abstrata de intelecção; é engajamento do corpo, inscrição num espaço, relação consigo e com os outros; e por meio dela acontece a apropriação do texto, o texto é incorporado, transformado pelo leitor em algo que dê sentido à sua relação com o mundo (cf. CHARTIER, 1994, p. 16).

O historiador francês - Roger Chartier - nos aponta, ainda, para dois tipos de textos, aqueles "sem qualidades, pragmáticos e práticos, e aqueles que possuem o estranho poder de fazer sonhar, levar à reflexão ou suscitar desejo" (CHARTIER, 2011, p. 266); são os últimos (aos quais denominamos literários) nosso maior interesse nessa pesquisa. Segundo Antonio Candido (2010, p. 30), o texto literário, como uma obra de arte, torna-se social, já que influencia na vida do sujeito leitor, modificando sua conduta e sua concepção de mundo ou reforçando seus sentimentos dos valores sociais. Por meio da obra de arte, o leitor pode proporcionar a si momento de mero prazer estético ou, ainda, refletir sobre questões complexas, confrontar sua realidade e conhecimento de mundo. 
A partir disso, torna-se necessário considerar a formação do sujeito leitor, o leitor de literatura. Partindo do princípio que o ser humano vive em sociedade e interage com ela a partir de suas representações, sua formação enquanto leitor está associada aos agentes sociais com os quais convive ao longo de sua vida, incluindo-se a instituição escolar e seus sujeitos. Dessa forma, nesse contexto, a leitura de literatura permite ao sujeito a interação com outros e o torna participante do sentimento de mundo; ou seja, a leitura é "sempre uma prática encarnada em gestos, em espaços, em hábitos" (CHARTIER, 1994, p. 13).

Assim, a prática do ato de ler estará sempre situada social e historicamente, e os sujeitos que constituem as diferentes comunidades em que se inserem compartilham modos, técnicas e práticas, criando com isso comunidades de leitores (CHARTIER, 1994, p. 27), com interesses e expectativas comuns em relação ao objeto escrito. Cada comunidade de leitores possui instrumentos e procedimentos próprios, legitimados pelo grupo, em cada uma delas há regras que especificam o que é lido, como é lido e como deve ser interpretado.

Segundo Chartier (1998), "a fragmentação [dessas comunidades de leitores] resulta das divisões entre as classes, dos processos diferentes de aprendizagem, das escolaridades mais ou menos longas, do domínio mais ou menos seguro da cultura escrita" (p. 98); assim, cada comunidade de leitores terá características específicas que a diferenciam das outras. As especificidades de cada comunidade de leitores circunscrevem as práticas de leitura de seus membros, o que quer dizer que, a aceitação ou não de um texto, a apropriação ou não de seu sentido estará ligada diretamente à relação construída com a escrita por cada leitor, no contexto de uma comunidade, com as ferramentas intelectuais (CHARTIER, 1994, p. 13) usadas no processo de leitura.

Todavia, é importante ressaltar que o trabalho do historiador (Roger Chartier) não demonstra uma organização das clivagens culturais segundo uma grade única do recorte social, ele defende a investigação de quais objetos impressos e gêneros textuais fazem parte de cada comunidade; aqui encontramos o ponto teórico que nos parece legitimar nossas investigações sobre as práticas de leitura dos jovens do século XXI, em particular, daqueles inseridos em um contexto específico de escolarização.

Nessa perspectiva, vemos que a formação de leitor literário é atravessada pelos agentes sociais aos quais ele está submetido ao longo de sua existência, ou seja, família, amigos, líderes religiosos, escola: cada comunidade pensada como inerente às histórias singulares de formação dos sujeitos leitores e como cambiante, em relação às demais, no processo de definição das quais cada leitor faz parte.

Esses agentes sociais têm cada qual papéis na formação de um leitor; todo indivíduo traz consigo um universo cultural formado por meio de sua interação pessoal, singular - com o contexto em que vive, quer dizer que a influência dos grupos na formação cultural/leitora desse sujeito se dá dentro e fora da escola:

[...] as expectativas e preferências refletem a complexidade das relações que envolvem sua formação como leitor, mesmo fora do circuito escolar. Seu gosto traz marcas do aprendizado de leitura, a partir da exposição, desde muito cedo, aos produtos da indústria cultural e ao contexto social em que vive. (MORTATTI, 1994, p. 102)

Ezequiel da Silva (1999, p. 165) corrobora com nossa compreensão ao afirmar que

[...] a leitura não é uma função que nasce e se desenvolve devido a um dom, vocação ou talento do indivíduo. Muito pelo contrário: a leitura 
é uma prática social que, para ser efetivada, depende de determinadas condições objetivas, presentes na sociedade como um todo [...]; uma pessoa dificilmente vai ler ou conviver como livros [...] se ela não for levada a valorizar a leitura como meio de adquirir conhecimento".

Nesse sentido, o que a escola escolhe ter em sua biblioteca institucional e as escolhas que os usuários da biblioteca, na condição de estudantes, fazem, talvez nos forneçam indícios não apenas de práticas de leitura literária, mas de como as comunidades de leitores se constituem e se legitimam no espaço escolar.

\section{Biblioteca: mediadora da leitura ou depósito de livros?}

Criadas com o intuito de reunir as publicações fundamentais para a formação intelectual homem, como uma busca pela posse do saber, as bibliotecas "buscavam oferecer a seus frequentadores aquilo que poderia tonar mais potente o seu olhar sobre si mesmo e sobre o mundo" (CHARTIER, 1998, p. 119). Deste modo, a instituição escolar nutrida de um diversificado acervo literário estará propícia à formação de leitores. Todavia, há uma relação dialética entre biblioteca e essa formação.

Não são desconhecidas em nosso país algumas situações lastimáveis de bibliotecas escolares: livros deteriorados, locais de difícil acesso, espaço funcionando para castigos ou depósito de livros amontoados sem qualquer classificação, ou, ainda, aquelas bibliotecas extremamente organizadas sem a possibilidade de manuseio dos objetos escritos, que vivem trancados como tesouros intocáveis aos estudantes. Diferentemente dessas realidades, consideramos que, em uma biblioteca, a disposição dos objetos culturais no espaço deve garantir a circulação do leitor de maneira fluente e espontânea, tendo livre acesso às prateleiras, onde, de acordo com Chartier (1998), "você [leitor] encontrará livros que não procura, como se fossem eles que o procurassem" (p. 119).

Intentando para esse encontro, o Instituto Federal do Espírito Santo (IFES)/Campus de Alegre conta com uma biblioteca capaz de referendar a formação leitora ali erigida, com estrutura organizada e fundamentada para esse fim, como vemos a partir das respostas dadas ao questionário apresentado aos representantes da biblioteca e como vemos a partir das imagens abaixo:

Foto 1: Visão panorâmica da Biblioteca do IFES /Campus de Alegre 


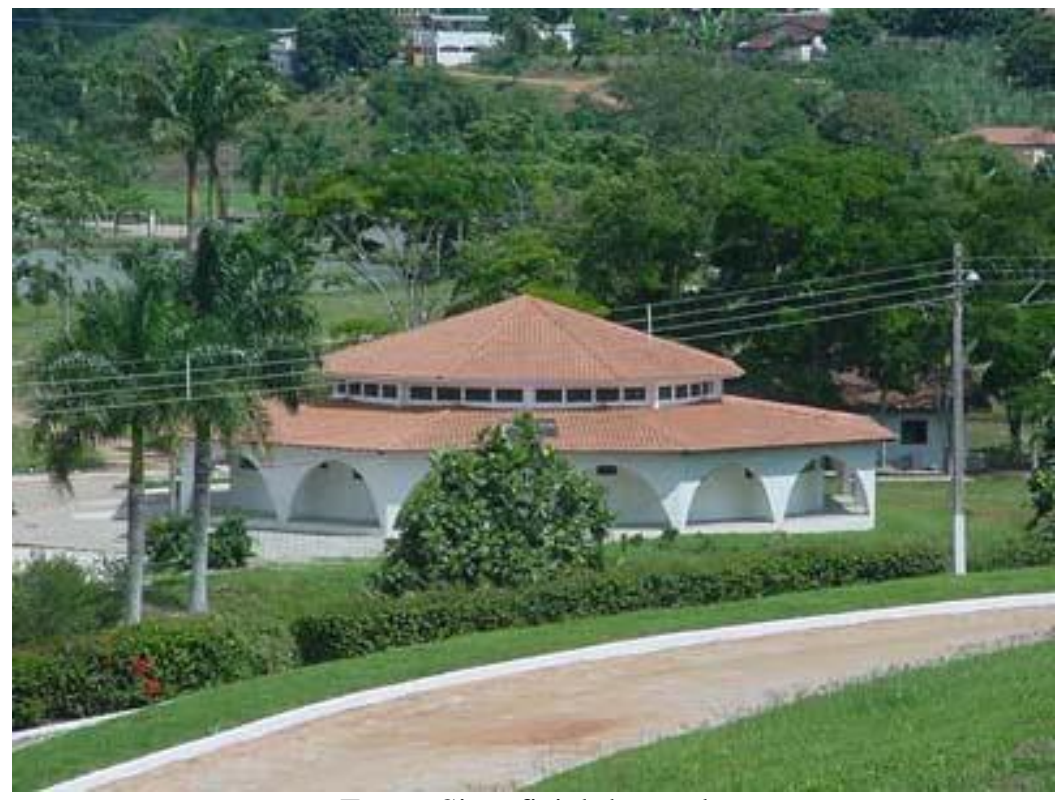

Fonte: Site oficial da escola

Foto 2: Espaço interno da Biblioteca do IFES /Campus de Alegre

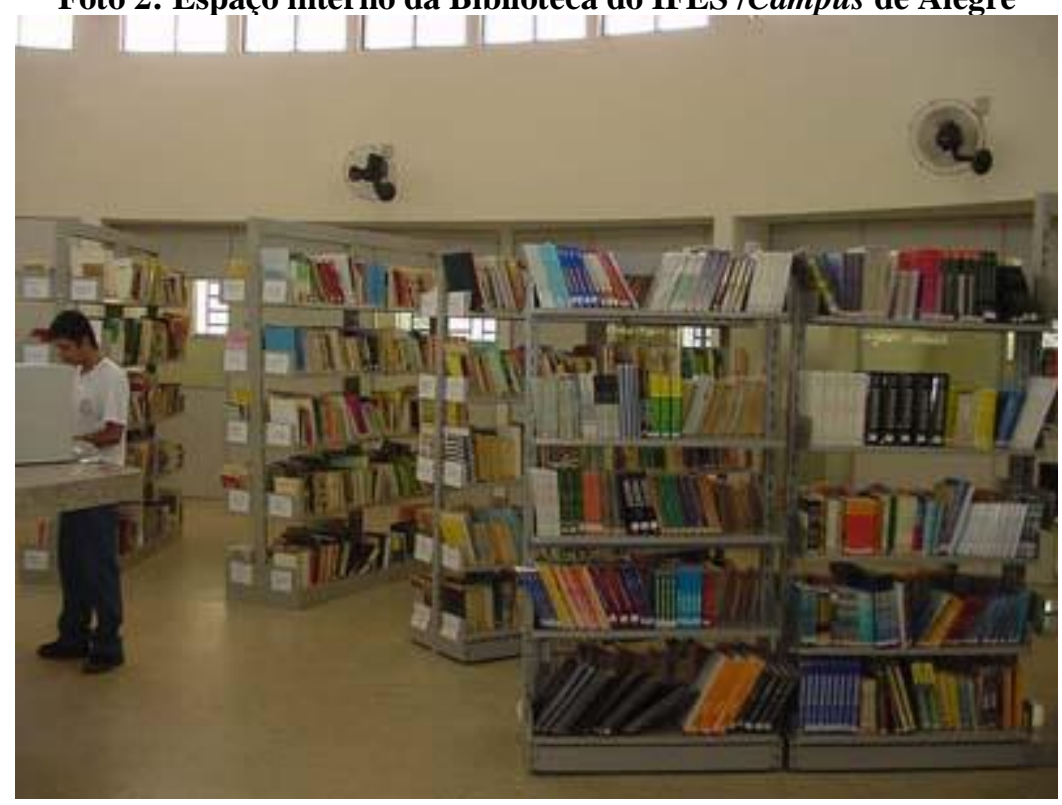

Fonte: Site oficial da escola

Nomeada como Biblioteca Monsenhor José Bellotti, foi inaugurada em novembro de 2005 e possui uma área de $512 \mathrm{~m}^{2}$. Conta atualmente com 681 obras classificadas como literatura. São livros destinados a várias comunidades de leitores. Há no acervo os livros considerados os best-sellers do momento contemporâneo e os chamados clássicos literários; a coletânea é constituída, principalmente, por doações de Programas do Governo Federal, como o Programa Nacional Biblioteca da Escola (PNBE).

As obras do acervo da biblioteca da escola estão organizadas em estantes cuja disposição possibilita que os visitantes circulem em seu interior. $\mathrm{O}$ espaço possui salas reservadas de estudo e leitura coletiva, sem contar uma ilha tecnológica que garante aos frequentadores a inserção no mundo da Internet e o acesso a uma biblioteca universal. Conquanto, as maneiras de ler ali refletem aquelas difundidas durante os séculos XII e XIV, é a leitura individual e silenciosa (PAULINO, 2001, p. 20). 
Vale salientar que, embora o acervo do IFES/ Campus de Alegre não conte com um trabalho específico de mediação entre alunos e servidores, há um espaço no site da escola destinado à divulgação das aquisições da biblioteca. Nesse contexto da era tecnológica, a biblioteca da instituição também conta com um sistema informatizado de catalogação e gerenciamento de empréstimos das obras, é o programa Pergamum Sistema integrado de Bibliotecas, usado em todos os campi do IFES; foi por meio desse recurso que obtivemos os dados apresentados e discutidos a seguir, a respeito dos empréstimos de obras literárias no ano de 2013.

\section{As obras literárias que os estudantes de ensino médio tomam emprestadas na biblioteca escolar}

Levando em consideração o custo de objetos culturais, como livro de literatura, no Brasil, e a localização do município de Alegre, interior do Estado do Espírito Santo; compreendemos a biblioteca escolar como uma das principais, senão a única, fonte física de encontro entre leitores com obras literárias. Por isso, fomos buscar no campus do Ifes em Alegre indícios das práticas de leitura dos jovens estudantes de ensino médio.

Em 2013, a Biblioteca Monsenhor José Bellotti realizou 867 empréstimos de livros literários, sendo 724 para alunos do Ensino Médio; esse total se refere ao número de livros de literatura que saíram da biblioteca, mas não faz separação entre leitores diferentes e renovação do empréstimo do mesmo livro pelo mesmo leitor. Por meio de informações fornecidas pela gestão da biblioteca, esses empréstimos foram feitos por apenas 161 alunos. Vale ressaltar que, de acordo com a secretaria da escola, no início do ano letivo de 2013 havia 599 alunos matriculados nos cursos técnicos integrados ao ensino médio, ou seja, um terço desses alunos usufruiu do acervo literário da instituição.

Entre os livros emprestados pela biblioteca em 2013, só aparecem cinco obras poéticas ( $O$ melhor da poesia brasileira, Nova antologia poética, de Vinícius de Moraes, Mar absoluto e outros poemas e Retrato Natural, Cecília Meireles, Os Lusíadas: edição comentada, Luiz Vaz de Camões e Para querer bem: antologia poética de Manuel Bandeira, organizada por Bartolomeu Campos de Queiros), que foram retiradas por alunos distintos, o que nos pareceu indiciar não haver um gosto formado pela leitura do texto poético.

Outra importante constatação na análise dos resultados se refere às obras consideradas canônicas, no contexto de comunidades escolares; isso porque há dois segmentos nos empréstimos desse campo: primeiro, somente duas obras integrais desse tipo aparecem na lista de empréstimos (Quincas Borba e Capitães da Areia), emprestadas também para três alunos diferentes; por outro lado, foram emprestadas também obras do campo erudito que fazem parte de uma série de adaptações para neoleitores (Coleção É só o começo, da editora L\&PM), são obras como O Alienista, A escrava Isaura, O cortiço, Dom Quixote, Romeu e Julieta, O triste fim de Policarpo Quaresma, entre outras. Em contraponto, as obras que lideram a lista das mais emprestadas são os famosos best-sellers, divulgados e muito influentes na sociedade geral. Observamos, na tabela abaixo (Tab.1), que, entre os treze livros mais emprestados pela biblioteca do IFES/Campus de Alegre, dez livros são esses best-sellers e três da Coleção É só o começo; não aparece nenhuma obra integral considerada canônica para o contexto de comunidades escolares. 
Tabela 1: Ranking das obras literárias mais emprestadas pela Biblioteca do IFES/Campus de Alegre para os alunos do Ensino Médio, em $20013^{1}$.

\begin{tabular}{|l|c|c|}
\hline \multicolumn{1}{|c|}{ Obras } & \multicolumn{1}{c|}{ Autores } & $\begin{array}{c}\text { Número de } \\
\text { empréstimos }\end{array}$ \\
\hline A cabana & Willian P. Young & 10 \\
\hline As aventuras de Robinson Crusoé: versão adaptada para neoleitores & Daniel Defoe & 10 \\
\hline Um amor para recordar & Nicholas Sparks & 10 \\
\hline Dom Quixote: versão adaptada para neoleitores & Miguel de Cervantes & 9 \\
\hline A escrava Isaura: versão adaptada para neoleitores & Bernardo Guimarães & 9 \\
\hline O cortiço: versão adaptada para neoleitores & Aluísio Azevedo & 9 \\
\hline O Hobbit & J. R. R Tolkien & 8 \\
\hline O código da Vinci & Dan Brown & 8 \\
\hline A guerra dos tronos & George R. R. Martin & 8 \\
\hline A vida na porta da geladeira & Alice Kuipers & 7 \\
\hline A revolução dos bichos & George Orwell & 7 \\
\hline O menino do pijama listrado & Jonh Boyne & 7 \\
\hline Senhor dos anéis - volume único & J. R. R Tolkien & 7 \\
\hline
\end{tabular}

Fonte: Pergamum - Sistema Integrado de Bibliotecas usado no IFES.

Esse dado indicia que os estudantes de nível médio, cuja faixa etária gira, majoritariamente, entre 14 e 18 anos, são leitores fortemente influenciados pela mídia (indústria cultural) e, principalmente, pelas leituras realizadas pelos outros colegas, de modo que a leitura realizada por um é replicada/repetida por outros. Talvez essa atitude possa ser explicada, para além das questões inerentemente ligadas à leitura, pela necessidade dos adolescentes de se sentirem participantes de comunidades, ou seja, de partilharem valores e práticas comuns.

\section{Os estudantes que mais leem, o que leem?}

Conhecendo as obras retiradas da biblioteca escolar, atinamos para os estudantes que usufruíram do acervo escolar. A Tab. 2 apresenta dados produzidos a partir da seguinte sequência de indagações, apresentadas à gestão da biblioteca escolar: a) quais são os mais assíduos estudantes frequentadores da biblioteca escolar?; e b) o que esses estudantes tomam de empréstimo? Os dados referentes a tais questões são apresentados abaixo:

Tabela 2: Relação das obras literárias retiradas da biblioteca pelos alunos que mais retiram livros do acervo escolar, em 2013

\begin{tabular}{|c|c|c|c|c|}
\hline Aluno & Sexo & Série & Quantidade & Obras literárias \\
\hline Aluno A & M & $2^{\mathrm{a}}$ & 11 & $\begin{array}{l}\text { O Senhor dos anéis - Volume Único } \\
\text { O anel dos nibelungos } \\
\text { A tormenta de espadas } \\
\text { O festim dos corvos } \\
\text { A fúria dos reis } \\
\text { A guerra dos tronos } \\
\text { O Silmarillion } \\
\text { A menina que roubava livros } \\
\text { A cabana } \\
\text { A dança dos dragões } \\
\text { O código da Vinci }\end{array}$ \\
\hline Aluno B & $\mathrm{F}$ & $1^{\mathrm{a}}$ & 11 & Alice: edição comentada \\
\hline
\end{tabular}

\footnotetext{
${ }^{1}$ Essa categoria se dá não pelo número de vezes que o livro foi emprestado para um mesmo aluno, e sim o número de leitores que os retiraram da biblioteca.
} 


\begin{tabular}{|c|c|c|c|c|}
\hline & & & & $\begin{array}{l}\text { Duda 3: a ressurreição } \\
\text { Como viver eternamente: cada minuto conta } \\
\text { Arthur e a guerra dos dois mundos } \\
\text { Diário do ouro } \\
\text { Comédias para se ler na escola: edição especial para } \\
\text { crianças. } \\
\text { A comédia dos anjos } \\
\text { Ana Z, aonde você vai? } \\
\text { Menina mãe } \\
\text { Comer, rezar e amar } \\
\text { A vida na porta da geladeira }\end{array}$ \\
\hline Aluno C & $\bar{M}$ & $1^{\mathrm{a}}$ & 10 & $\begin{array}{l}\text { O triste fim de Policarpo Quaresma: versão adaptada } \\
\text { para neoleitores } \\
\text { Justino: o retirante } \\
\text { O menino Grapiúna } \\
\text { Capitães da areia } \\
\text { Diário de Biloca } \\
\text { Desenho mudo } \\
\text { A guerra dos tronos } \\
\text { O Silmarillion } \\
\text { A cabana } \\
\text { A vida na porta da geladeira }\end{array}$ \\
\hline Aluno D & $\mathrm{F}$ & $1^{\mathrm{a}}$ & 9 & $\begin{array}{l}\text { O senhor dos anéis - Volume Único } \\
\text { Duda 3: a ressurreição } \\
\text { Como viver eternamente: cada minuto conta } \\
\text { O menino do pijama listrado } \\
\text { Água viva: ficção } \\
\text { O outro lado do tabuleiro } \\
\text { O morro dos ventos uivantes } \\
\text { O caçador de pipas } \\
\text { Um amor para recordar }\end{array}$ \\
\hline Aluno E & $\mathrm{F}$ & $1^{a}$ & 9 & $\begin{array}{l}\text { O guardião de memórias } \\
\text { A companheira de viagem } \\
\text { Agua viva: ficção } \\
\text { Menina mãe } \\
\text { A marca de uma lágrima } \\
\text { Copo vazio } \\
\text { Cidade do sol } \\
\text { A cabana } \\
\text { A vida na porta da geladeira }\end{array}$ \\
\hline
\end{tabular}

Fonte: Pergamum - Sistema Integrado de Bibliotecas usado no IFES.

Entre os cinco alunos que mais usufruíram das obras literárias da biblioteca escolar (Tab. 2), quatro eram alunos dos primeiros anos do Ensino Médio, o que nos sugere algumas hipóteses. Considerando que a escola em questão funciona, para muitos alunos, como internato e considerando que os estudantes dos primeiros anos estão iniciando seu itinerário na escola (ou seja, tendem a ter redes de sociabilidade mais frágeis, no espaço escolar, em função do pouco tempo de inserção na instituição), a distância da família e de casa é suprida, entre outras formas, pela frequência à biblioteca escolar e, consequentemente, pela leitura; assim, a leitura literária pode servir como um alento, como uma forma de evitar que se sintam ainda mais sozinhos e solitários. Progressivamente, com o engajamento em outras atividades e o fortalecimento de vínculos sociais de outra ordem, a leitura literária vai perdendo espaço ou importância.

Vale pensar também que, como estão no início do curso técnico, esses alunos do primeiro ano não estão imersos ainda no contexto e rotina de formação técnica, isto é, o currículo dos primeiros anos possui menos disciplinas técnicas, sem contar que escola funciona em tempo integral, os alunos estudam em sala de aula/aula de campo, 
aproximadamente, oito horas por dia, sem falar dos estudos extraclasses (trabalhos, atividades de casa, provas, entre outras), o que nos sugere que os alunos dos segundos e terceiros anos, mais preocupados com essa rotina, se afastam da leitura literária.

Em relação a esses alunos que mais buscaram livros emprestados na biblioteca do campus, eles pegaram onze livros diferentes durante o ano de 2013, ou seja, são leitores que consumiram, em média, no mínimo, um livro por mês letivo, sem contar a leitura sem a contribuição desse agente social. Dado que mostra que nossa desconfiança em relação à atribuição de um rótulo de não leitores aos sujeitos da sociedade contemporânea, no mínimo, precisa ser relativizado.

Outro aspecto a ser destacado é o atinente à necessidade de apropriação do texto, à necessidade de sua transformação em algo que dê sentido à vida ou que participe do processo de atribuição de sentido à vida e às experiências: parece-nos que a leitura literária participa desse processo, ajudando que os estudantes que iniciam sua vida naquela instituição escolar em particular encontrem razões para permanecer, enfrentar e transformar o espaço-tempo em que vivem.

\section{Considerações Finais}

Ao nos debruçarmos sobre a biblioteca escolar de uma instituição pública e sobre os empréstimos de livros literários realizados por estudantes dessa instituição, constatamos, por meio dos dados levantados junto à instituição e produzidos por meio da Tab. 1 e da Tab. 2: a existência de estudantes que leem (um terço frequenta a biblioteca; há estudantes que leem em média um livro por mês); a existência de um prédio compatível com a função social da biblioteca; e, enfim, a existência de um acervo de qualidade, com excelentes obras literárias.

No entanto, conforme pontuamos no início do texto, a leitura é produção de sentidos e os sentidos se produzem em processos enunciativos concretos: para isso, é preciso que se estabeleçam relações intersubjetivas. A fragilidade vista, assim, não está relacionada à questão do acervo e de sua organização, nem mesmo à falta de leitores, como apontamos anteriormente. Mas o que nos chamou a atenção foi a ausência de uma prática de divulgação e mediação desse acervo: segundo o responsável pela biblioteca, a escola não dispõe atualmente de nenhuma ação, além do site da instituição, que faça fluir a indicação ou o próprio material de leitura para o destinatário-alvo - os alunos. A biblioteca armazena os objetos culturais, que permanecem à espera de seus leitores; sem nenhuma ação que instigue, ou favoreça o contato, ou mesmo faça a mediação - via instituição de ensino - para que os jovens leitores cheguem até seus textos. Na escola pesquisada, não se viu, a partir dos dados produzidos, ação que seja capaz de romper com a limitação do conhecido e leve o leitor a ampliar seus horizontes.

Em contrapartida, há um trabalho de marketing muito bem executado pela mídia e grandes indústrias do livro em relação aos best-sellers; são propagandas, adaptações para o cinema, exposição em livrarias, canais da Internet, influenciadores digitais, capas chamativas, listas de mais vendidos, enfim, todo um arcabouço mercadológico que influência e conduz as escolhas literárias no século XXI. Dessa forma, as obras literárias que são tomadas de empréstimo pelos estudantes da instituição sugerem por um lado a indicação de docentes (a minoria delas, e quase sempre em versões adaptadas, o que aponta para outras investigações) e por outro e mais provavelmente, o são por meio das trocas entre os próprios estudantes em face do 
trabalho massivo de marketing promovidos pelas grandes corporações editoriais, com seus lançamentos mundiais.

Essas informações e constatações nos fazem supor, a partir dos indícios aqui considerados, que o perfil de estudantes-leitores usuários da biblioteca e que tomam de empréstimo o acervo ficcional ali existente é o de sujeitos fortemente influenciados pela indústria cultural.

A conquista por parte da escola de um acervo respeitável por si só não contribui com a formação do leitor, há necessidade de mediar esse acesso. A prática leitora além da leitura de massa, a partir dos empréstimos realizados pela biblioteca escolar, é praticamente ignorada, o que nos faz pensar no trabalho realizado com a leitura literária de maneira mais ampla. Sem um trabalho sistemático de mediação, no espaço escolar, de práticas de leitura de textos literários que ultrapassem a arte média ou os produtos da indústria cultural, sempre haverá alunos que não compreenderão a literatura que escapa ao perfil dos best-sellers e que se coloca de modo inventivo e crítico, pela falta de um conhecimento e formação anteriores que contribuam para sua fruição e apropriação.

As instituições de ensino parecem-nos que devam priorizar, então, políticas de mediação da atividade leitora, proporcionando divulgação de seu acervo literário, mostrando outras obras além das divulgadas pela mídia, promovendo atividades de socialização das apropriações das leituras e construção de parcerias entre os agentes culturais de leitura (professores, bibliotecários, principalmente). Esses últimos processos (atividades de socialização de leituras e construção de parcerias) nos parecem vitais à constituição e consolidação de comunidades de leitores e, principalmente, à invenção e partilhamento de ferramentas intelectuais que permitam aos estudantes questionarem as obras literárias que repetem ad nauseam fórmulas previsíveis que embotam o propósito estético das obras de ficção.

\section{Referências}

CANDIDO, A. Literatura e sociedade. Rio de Janeiro: Ouro sobre azul, 2010.

CHARTIER, R. (Org). Práticas de leitura. São Paulo: Estação Liberdade, 2011.

. A ordem dos livros: leitores, autores e bibliotecas na Europa entre os séculos XIV e XVIII. Tradução Mary Del Priore. Brasília, DF: UnB, 1994.

A aventura do livro: do leitor ao navegador: conversações com Jean Lebrun/ Roger Chartier. São Paulo: UNESP, 1998.

Aula Inaugural no Collége de France. In: ROCHA, J. (Org.). Roger Chartier: a força das representações: história e ficção. Chapecó, SC: Argos, 2011, p. 249 - 285.

INSTITUTO FEDERAL DO ESPÍRITO SANTO (IFES) $<$ http://alegre.ifes.edu.br//biblioteca-monsenhor-jose-bellotti> Acesso em: 5 abr. 2014.

MARISA, L., ZILBERMAN, R. A formação da leitura no Brasil. 3.ed. São Paulo: Ática, 1998. 
MORTATTI, M. do R. Leitura e formação do gosto: por uma pedagogia do desafio do desejo. Série Ideias n.13. São Paulo: FDE, 1994.

PAIM, E. A.; PRIGOL, V. Mediação e Formação De Leitores. In: CONGRESSO DE LEITURA DO BRASIL,17, 2009, Campinas. Anais do $17^{\circ}$ COLE, Campinas, SP,: ALB, 2009. Disponível em: http://www.alb.com.br/portal.html. Acesso em: 5 set. 2014. ISSN: 2175-0939

REZENDE, N. L. et al. (Org.) Leitura subjetiva e ensino de literatura. São Paulo: Alameda, 2013.

SILVA, M. C. da. Uma história da formação do leitor no Brasil. Rio de Janeiro: EDUERJ, 2009.

Recebido em 20 do setembro de 2018

Aceito em 22 de novembro de 2018 